\title{
Synthesis and extracellular accumulation of silver nanoparticles by employing radiation-resistant Deinococcus radiodurans, their characterization, and determination of bioactivity
}

\author{
This article was published in the following Dove Press journal: \\ International Journal of Nanomedicine \\ 29 January 2015 \\ Number of times this article has been viewed
}

\author{
Rasika R Kulkarni \\ Nayana S Shaiwale \\ Dileep $N$ Deobagkar \\ Deepti D Deobagkar \\ Molecular Biology Research \\ Laboratory, Center of Advanced \\ Studies, Department of Zoology, \\ University of Pune, Pune, India
}

Correspondence: Deepti Deobagkar Molecular Biology Research Laboratory, Center of Advanced Studies, Department of Zoology, University of Pune, Ganeshkhind Road, Pune 4I I007, India Tel +9l 9921184871

Email deepti.deobagkar@gmail.com

\begin{abstract}
There has been rapid progress in exploring microorganisms for green synthesis of nanoparticles since microbes show extraordinary diversity in terms of species richness and niche localization. Microorganisms are easy to culture using relatively inexpensive and simple nutrients under varied conditions of temperature, pressure, $\mathrm{pH}$, etc. In this work, Deinococcus radiodurans that possesses the ability to withstand extremely high radiation and desiccation stress has been employed for the synthesis of silver nanoparticles (AgNPs). D. radiodurans was able to accumulate AgNPs in medium under various conditions, and process optimization was carried out with respect to time, temperature, $\mathrm{pH}$, and concentration of silver salt. AgNPs were characterized using UV/vis spectroscopy, scanning electron microscopy, transmission electron microscopy, X-ray diffraction, energy-dispersive X-ray spectroscopy, and Fourier transform infrared spectroscopy. The microbially synthesized AgNPs exhibited good antimicrobial activity against both Gram-negative and Gram-positive organisms and anti-biofouling activity. Their ability to inhibit growth and proliferation of cancer cell line was also examined, and it could be seen that AgNPs synthesized using D. radiodurans exhibited excellent anticancer activity.
\end{abstract}

Keywords: Deinococcus radiodurans, silver nanoparticles, anticancer, radiation resistance, antibacterial, anti-biofouling

\section{Introduction}

Nanotechnology has gained tremendous public interest due to the possibility of applications of nanomaterials in many areas such as industry, agriculture, medicine, diagnostics, and drug delivery. Nanomaterials act as a connecting link between bulk materials and molecular and atomic structures. They exhibit completely new and improved properties when compared with the bulk material, particularly with respect to specific characteristics such as size, distribution, morphology, and spectral and electrical properties. Silver nanoparticles (AgNPs), in particular, have been demonstrated to have diverse potential applications. The strong antibacterial activity against a wide range of pathogens and their potential in wound healing are among the most exploited applications of AgNPs in the medical field, due to which they are used in advanced bandages and dressing burn wounds. ${ }^{1}$ AgNPs have been exploited in designing silica-silver core-shell nanoparticles and utilized for rapid detection of microbes, proteins, and antibodies. ${ }^{2,3}$ AgNPs have also been used in bone cements in artificial joint replacements, since their presence drastically reduced the wear and tear of the polymer. ${ }^{4,5}$ Although AgNPs have promising role in biomedical applications, human toxicity and environmental hazards posed by 
them cannot be neglected. It is reported that indiscriminate use of AgNPs and silver-containing medications has led to increased cases of argyria. ${ }^{6}$ In addition, nano-antimicrobials when released in natural systems may pose a serious threat to the beneficial bacteria in these systems, thereby leading to eutrophication. $^{7}$ Therefore, a better understanding about the biological interactions of these nanoparticles is required to develop safe nano-antimicrobials.

Currently, many methods have been reported for the synthesis of AgNPs using chemical, physical, photochemical, and biological routes. ${ }^{8}$ The chemical and physical methods of nanosilver production are often expensive and also involve the use of toxic and hazardous chemicals, which may pose potential environmental and biological risks. To reduce the dreadful effects of chemical synthesis and to obtain novel nanoparticles at a cheaper rate, green synthesis is increasingly being explored. An ecofriendly solvent system and availability of biocompatible reducing and capping agents are the basic requirements for green synthesis. ${ }^{9}$ In addition, biological methods are inexhaustible, economic, and can be operated at ambient temperature and pressure conditions. Various microbes are known to reduce the silver $\left(\mathrm{Ag}^{+}\right)$ions to form $\mathrm{AgNPs}$, most of which are found to be spherical particles. ${ }^{10}$ Studies have indicated that culture supernatants of several bacteria like Escherichia coli, Enterobacter cloacae, Klebsiella pneumoniae, Bacillus spp., Lactobacillus acidophilus, Staphylococcus aureus, and several psychrophilic bacteria like Pseudomonas antarctica, Pseudomonas proteolytica, Pseudomonas meridiana, Arthrobacter kerguelensis, and Arthrobacter gangotriensis can be used to generate AgNPs. ${ }^{8,11,12}$ Some of these microorganisms can survive and grow even at high metal ion concentrations. Metal-reducing bacteria are exposed to extreme environmental conditions and possess specific defense mechanisms to quell such stresses, including the toxicity of foreign metal ions or metalloids ${ }^{13,14}$ and hence can be utilized in the synthesis of nanoparticles. Dissimilatory metal-reducing bacteria Geobacter sulfurreducens have shown the ability of actively reducing soluble $\mathrm{Pd}(\mathrm{II})$ to $\mathrm{Pd}(0)$ extracellularly, thus reducing the toxicity of metal ion. ${ }^{15} \mathrm{Fe}(\mathrm{III})$-reducing bacterium Shewanella algae reduces $\mathrm{Au}^{3+}$ ions in anaerobic environments to form 10-20 nm gold nanopaticles ${ }^{16}$ and is capable of producing extracellular M-substituted magnetite nanoparticles using akaganeite and dopants in soluble form. ${ }^{17}$ Deinococcus radiodurans, the most radiation-resistant organism having a potential to sustain the presence of various heavy metals such as Fe(III), Cr(VI), U(VI), and Tc(VII), ${ }^{18}$ has not yet been explored for its ability to synthesize nanoparticles. Genome manipulation has been extensively used to clone and express genes encoding bioremediation functions in Deinococcus, for example, the use of merA to detoxify highly toxic, thiolreactive $\mathrm{Hg}(\mathrm{II})$, to much less toxic and nearly inert elemental and volatile $\mathrm{Hg}(0),{ }^{19}$ the tod and xyl operons to oxidize toluene and reduce $\mathrm{Cr}(\mathrm{VI})$ in sediment microcosms, ${ }^{20}$ and $p h o N$ that is capable of bioprecipitation and biorecovery of uranium. ${ }^{21}$ Previously, the S-layer lattices from $D$. radiodurans have been successfully used as a biotemplate for guided self-assembly of commercially procured hexagonal and honeycomb-ordered arrays of the dendrimer-encapsulated platinum nanoparticles, citrate-capped gold nanoparticles, and various species of $\mathrm{CdSe} /$ $\mathrm{ZnS}$ core-shell quantum dots. ${ }^{22}$ The present study involves the synthesis and extracellular accumulation of AgNPs using the bacterium D. radiodurans. UV/vis spectroscopy, transmission electron microscopy (TEM), scanning electron microscopy (SEM), and energy-dispersive spectroscopy (EDX) were used to characterize these AgNPs. In addition, Fourier transform infrared spectroscopy (FTIR) was performed for functional group identification, and crystal structure studies were performed using X-ray diffraction (XRD).

This report highlights, for the first time, the use of radiation- and desiccation-resistant $D$. radiodurans for the synthesis of AgNPs. These nanoparticles exhibit excellent antibacterial, anti-biofouling, and anticancer activity.

\section{Materials and methods Materials}

D. radiodurans strain used was R1 ATCC BAA-816. Silver nitrate $\left(\mathrm{AgNO}_{3}\right)$ was purchased from Merck (Mumbai, India). Tryptone glucose yeast (TGY) extract broth and Luria-Bertani (LB) broth were purchased from HiMedia (Mumbai, India). E. coli NCIM 2739, Proteus vulgaris NCIM 2027, and Pseudomonas aeruginosa NCIM 2948, which were procured from National Collection of Industrial Microorganisms (Pune, India), and S. aureus and Bacillus subtilis (soil isolates) were used for antibacterial assay. MTT (3-(4,5-dimethylthiazol-2-yl)-2,5-diphenyltetrazolium bromide) was purchased from Sigma-Aldrich Co. (St Louis, MA, USA) for cytotoxicity studies.

\section{Strain and culture conditions}

D. radiodurans strain $\mathrm{R} 1 \mathrm{ATCC} \mathrm{BAA}-816$ was grown aerobically in TGY ( $1 \%$ bacto tryptone, $0.5 \%$ bacto yeast extract, $0.1 \%$ glucose) broth with agitation (160 rpm), or on TGY-agar plates $(1.5 \%$ bacto agar $)$ at $32^{\circ} \mathrm{C}$. Bacterial growth was assessed by measuring turbidity (optical density at $600 \mathrm{~nm}, \mathrm{OD}_{600}$ ) of broth cultures or by determining colony-forming units (CFU) on TGY agar plates incubated at $32^{\circ} \mathrm{C}$ for 48 hours. 


\section{Synthesis and extracellular accumulation of AgNPs}

Overnight-grown culture of $D$. radiodurans was spun at $5,000 \mathrm{rpm}$ for 10 minutes, and the pellet thus obtained was resuspended in fresh TGY and incubated at $32^{\circ} \mathrm{C}$ with $160 \mathrm{rpm}$ till the culture attained an $\mathrm{OD}_{600}$ of 0.6. The midlog phase culture of $D$. radiodurans was adapted for 2 hours using $1 \mathrm{mM} \mathrm{AgNO}_{3}$. The adapted culture was spun at 5,000 rpm for 10 minutes, and the pellet was resuspended in the TGY with different concentrations of $\mathrm{AgNO}_{3}(1 \mathrm{mM}, 2.5 \mathrm{mM}, 5 \mathrm{mM}$, and $10 \mathrm{mM}$ ) for 24 hours. The bioreduction and extracellular accumulation of the silver ions in the solution using D. radiodurans were monitored at regular intervals by sampling the supernatant and measuring the absorption spectrum of the solution using UV/vis spectrophotometer at a resolution of $1 \mathrm{~nm}$. Appropriate controls (inoculated medium without $\mathrm{AgNO}_{3}$ and uninoculated medium with $\mathrm{AgNO}_{3}$ salt) were run simultaneously. UV/vis spectra of these sample aliquots were recorded as a function of time of reaction from $400 \mathrm{~nm}$ to $800 \mathrm{~nm}$ on a UV/vis dual-beam spectrophotometer at room temperature $\left(28^{\circ} \mathrm{C}\right)$.

\section{Characterization of AgNPs}

The preliminary characterization of the AgNPs was performed using UV/vis spectroscopy technique (Jasco dualbeam spectrophotometer V-630). UV/vis spectrum of the D. radiodurans supernatant (different time interval cultures were spun at 5,000 rpm for 10 minutes) was taken in order to check the optimum time when maximum production of AgNPs was observed using different concentrations of $\mathrm{AgNO}_{3}$ solution ( $1 \mathrm{mM}, 2.5 \mathrm{mM}, 5 \mathrm{mM}$, and $\left.10 \mathrm{mM}\right)$. Different $\mathrm{pH}$ ranges $(4.8,6.8$, and 8.8$)$ and temperatures $\left(20^{\circ} \mathrm{C}, 32^{\circ} \mathrm{C}\right.$, and $\left.37^{\circ} \mathrm{C}\right)$ were also optimized. For FTIR analysis, $500 \mu \mathrm{L}$ of the synthesized AgNPs $(2.5 \mathrm{mM})$ was lyophilized for 30 minutes, and the pellet thus obtained was resuspended in chloroform. The size and morphological characterization of the synthesized AgNPs were carried out using SEM and TEM (Technai F-30). TEM sample was prepared on 400 mesh carbon-coated copper grid, and silicon wafer was used for SEM sample preparation. Elemental analysis to confirm the presence of AgNPs in the test sample was performed using SEM-EDX (Quanta-200, 3D dual beam, source used - tungsten thermionic emission). EDX spectrum was recorded in the spot-profile mode by focusing the electron beam onto a region on the surface coated with silicon wafer. A thick film of synthesized AgNPs was made on a piece of glass slide; film was allowed to dry and used for XRD analysis.

\section{Antibacterial assay Agar well diffusion method}

Three Gram-negative bacteria E. coli NCIM 2739, P. vulgaris NCIM 2027, and P. aeruginosa NCIM 2948, and two Grampositive bacteria $S$. aureus and $B$. subtilis (soil isolates) were grown overnight in LB medium and spun at 5,000 rpm for 5 minutes. The pellet was washed with phosphate-buffered saline and resuspended in LB medium. The antibacterial activity was tested using agar well diffusion method. ${ }^{23}$ One hundred microliters of the suspended culture was spread uniformly on LB plates. The solid medium was then gently punctured with the help of cork borer to make wells, and $50 \mu \mathrm{L}$ of the synthesized AgNPs $(150 \mu \mathrm{g} / \mathrm{mL})$ was added in the respective well. The plates were incubated at $37^{\circ} \mathrm{C}$ for 24 hours. The antibacterial activity was assayed by measuring the diameter of the inhibition zone formed around the well. Kanamycin $(5 \mathrm{mg} / \mathrm{mL})$, ampicillin $(5 \mathrm{mg} / \mathrm{mL})$, and streptomycin $(5 \mathrm{mg} / \mathrm{mL})$ were used as positive controls, while sterile water served as a negative control.

\section{Standard dilution micromethod}

Antimicrobial activities of the synthesized AgNPs were assessed using the standard dilution micromethod with E. coli and $S$. aureus as representative Gram-negative and Grampositive organisms. A concentration of $10^{6} \mathrm{CFU} / \mathrm{mL}$ of each bacterial culture was exposed to $150 \mu \mathrm{g} / \mathrm{mL}$ concentration of AgNP solution; in the corresponding control, deionized water was added, and all flasks were incubated for 3 hours at $37^{\circ} \mathrm{C}$ with continuous shaking (200 rpm). Aliquot from each culture was withdrawn after 3 hours, and the growth of bacteria was monitored by plating the culture on Luria agar plates and measuring the CFU per milliliter. The counts from three independent experiments corresponding to a particular sample were averaged.

\section{Anti-biofouling assay}

The $S$. aureus and $P$. aeruginosa cultures were grown overnight in 96 -well microtiter plate at $37^{\circ} \mathrm{C}$. One hundred microliters of bacterial suspension along with different concentrations of AgNPs $(15-120 \mu \mathrm{g})$ was pipetted to each well of a 96-well microtiter plate and incubated at $37^{\circ} \mathrm{C}$. After 24 hours of incubation, the medium was discarded, and wells were thoroughly washed with phosphate-buffered saline ( $\mathrm{pH} 7.2$ ). One hundred microliters of $0.1 \%$ crystal violet was added to each well and left for 30 minutes. The stain was then discarded, and the plate was thoroughly washed. For quantification of attached cells, the crystal violet was solubilized in absolute ethanol, and the absorbance was measured 
at $570 \mathrm{~nm} .^{24}$ The OD value was used as an index to observe the ability of these organisms to form biofilm. Reduction of the biofilm was correlated with the AgNPs treatment to the cells. These experiments were carried out in triplicates, and the average values were calculated.

\section{Anticancer activity Cytotoxicity assay}

The mammalian breast cancer cell line (MCF-7) was utilized to examine the cytotoxic effect of synthesized AgNPs by using MTT assay and colony-forming assay. ${ }^{25} \mathrm{MCF}-7$ cells $(7,000$ cells/well) were seeded into a 96-well plate and exposed to a concentration range of 0-30 $\mu \mathrm{g}$ of AgNPs. After 24 hours of incubation, $20 \mu \mathrm{L}$ of $5 \mathrm{mg} / \mathrm{mL}$ MTT was added to each well and further incubated for 3 hours. Medium was removed, and $150 \mu \mathrm{L}$ of dimethyl sulfoxide was added. Plate was covered with foil and incubated on orbital shaker for 15 minutes. Absorbance was read at $550 \mathrm{~nm}$ with a reference filter of $660 \mathrm{~nm}$. The percent viability was calculated using the following formula.

$$
\% \text { Viability }=\frac{\Delta \mathrm{A} 550(\text { treated })}{\Delta \mathrm{A} 550(\text { control })} \times 100
$$

\section{Colony-forming assay}

The breast cancer cells (MCF-7) (50 cells/well) were seeded into a 24-well plate and incubated overnight. These cells were treated with different concentration $(0-7.5 \mu \mathrm{g})$ values below lethal dose $\left(\mathrm{LD}_{50}\right)$ of nanoparticles for 10 days, medium was removed, and cells were fixed using chilled ethanol. Cells were stained with crystal violet $(0.1 \%$ in ethanol) for 30 minutes. The plate was washed with water and allowed to dry. Numbers of colonies were counted. Percent viability was calculated using the following formula.

$$
\% \text { Viability }=\frac{\text { Colony count in treated }}{\text { Colony count in untreated }} \times 100
$$

\section{Statistical analysis}

Statistically significant differences between groups were determined using the Student's $t$-test and analysis of variance.

\section{Results and discussion Microbial synthesis of AgNPs}

Microbially synthesized AgNPs were reddish brown in color. Figure 1A shows a color change from yellow to reddish brown after incubation of $D$. radiodurans in the presence of $\mathrm{AgNO}_{3}$, which was indicative of the synthesis of AgNPs.
Spectrophotometric absorption measurements (UV/vis) in the wavelength range of $400-450 \mathrm{~nm}$ are used in characterizing the AgNPs. ${ }^{26,27}$ Figure 1B represents the UV/vis spectrum of culture supernatant containing AgNPs indicating the surface plasmon resonance centered at approximately $426 \mathrm{~nm}$, confirming the extracellular accumulation of AgNPs in the solution. Microbial synthesis of nanoparticles with different sizes and shapes depends on the organisms involved, concentration of $\mathrm{AgNO}_{3}$, temperature, $\mathrm{pH}$, and incubation period. ${ }^{28}$ To determine the influence of these factors on AgNPs synthesis, the experiment was carried out with variable concentrations of $\mathrm{AgNO}_{3}$ salt, temperatures, times of incubation, and $\mathrm{pH}$. A prominent absorption peak was seen at $426 \mathrm{~nm}$, which is characteristic of AgNPs synthesized at $32^{\circ} \mathrm{C}$ (Figure 1C), pH 6.8 (Figure 1D), and an $\mathrm{AgNO}_{3}$ concentration of $2.5 \mathrm{mM}$ (Figure 1E) when incubated for 24 hours (Figure 1F). A progressive increase in the characteristic peak with increase in reaction time is a clear indication of nanoparticles formation. It is well studied that though AgNPs have highly spherical and face-centered cubic crystal structure, various anisotropic shapes can be grown by controlling the assembly of metal atoms in the solution. ${ }^{26,29,30}$ Different sizes and shapes of AgNPs exhibit different spectra and can be used in different applications.

\section{SEM and TEM analysis}

Microscopic techniques such as SEM and TEM were utilized to characterize the morphology of nanoparticles. The SEM analysis showed that the synthesized AgNPs were spherical in shape (Figure 2A). To obtain better resolution, the AgNPs were scanned using TEM (Figure 2B). From the TEM image, it is evident that the entire surface of the grid was evenly spread, and the AgNPs were well dispersed. The particle size histogram revealed that the average particle size of the AgNPs was $16.82 \mathrm{~nm}$ as represented in Figure $2 \mathrm{C}$. The size of nanoparticles ranges from $4 \mathrm{~nm}$ to $50 \mathrm{~nm}$ with maximum percentage of particles of 15-20 nm and some particles of 5-8 nm sizes, while a very small percentage with diameters ranging from $45 \mathrm{~nm}$ to $50 \mathrm{~nm}$ could be visualized (data not shown). These variations in shape and size of nanoparticles synthesized by biological systems are common. ${ }^{31}$ TEM images for other preparation conditions using different concentrations of $\mathrm{AgNO}_{3}, 5 \mathrm{mM}$ and $10 \mathrm{mM}$, were also obtained. The average size observed for $2.5 \mathrm{mM}$ was $17 \mathrm{~nm}$ (Figure 3A), which was consistent with previous data. The concentration of $5 \mathrm{mM}$ exhibited an average size of $14.41 \mathrm{~nm}$ (Figure 3B), while $10 \mathrm{mM}$ showed an average size of $13.45 \mathrm{~nm}$ (Figure 3C). There was no significant difference observed in size of AgNPs synthesized using $2.5 \mathrm{mM} \mathrm{AgNO}_{3}$ salt and other concentrations used 
A
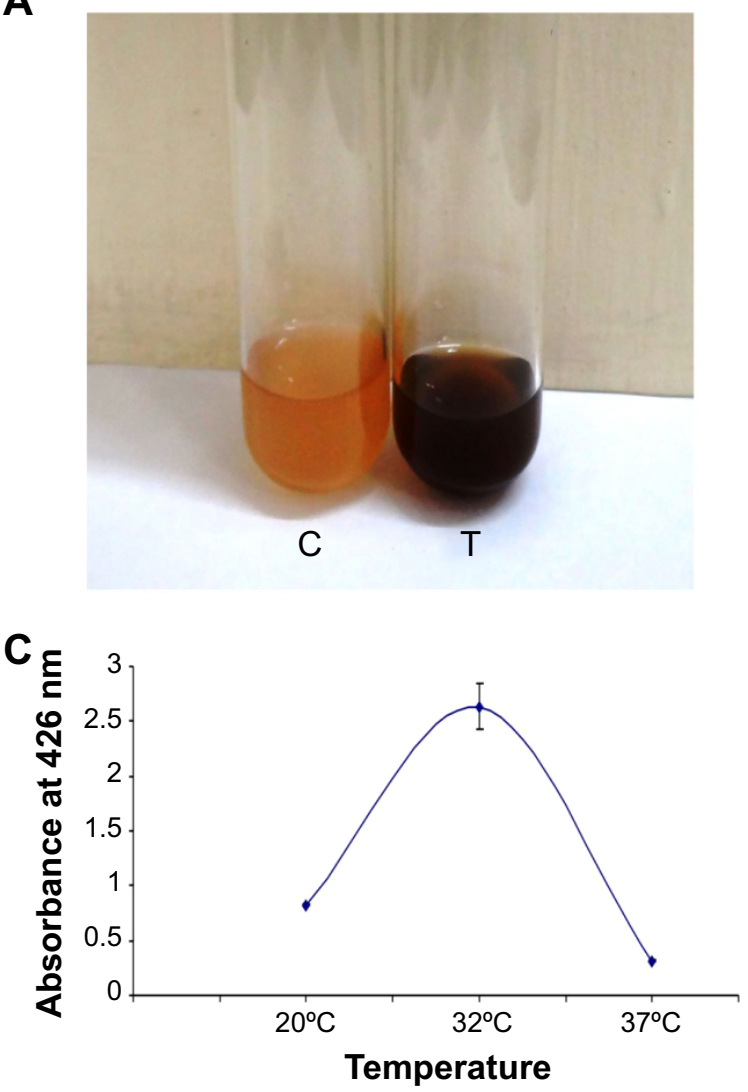

E

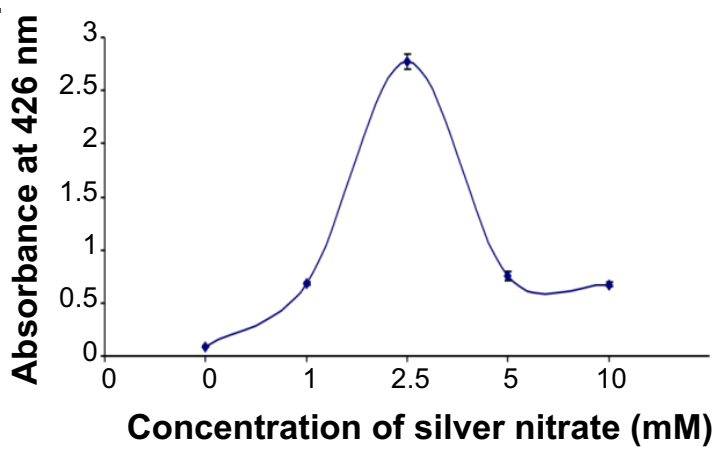

B

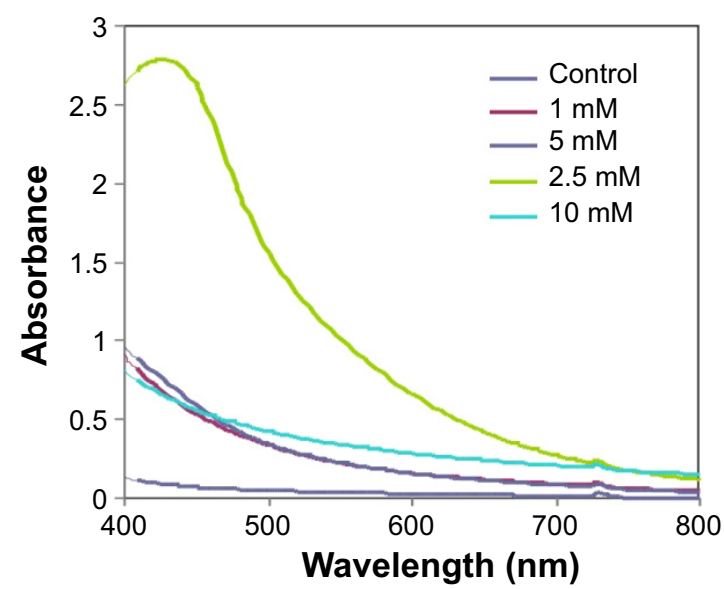

D

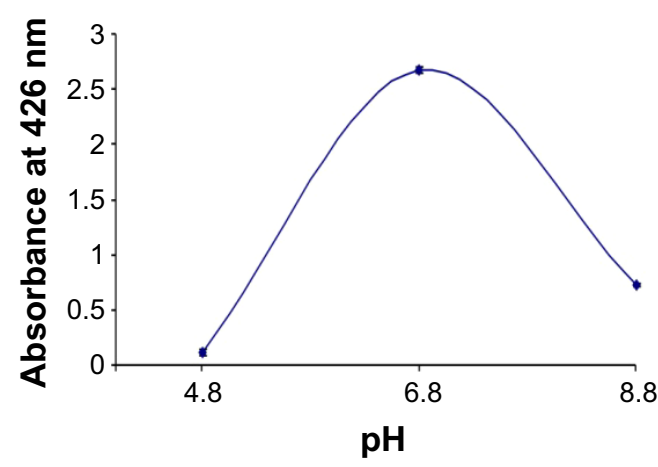

$\mathbf{F}$

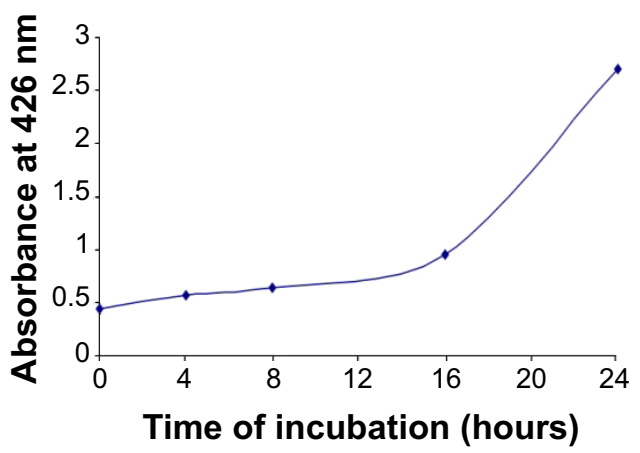

Figure I Synthesis and optimization of AgNPs.

Notes: (A) Tubes containing the culture supernatant before $(\mathrm{C}$ - control) and after ( $\mathrm{T}$ - test) immersion of Deinococcus radiodurans in $2.5 \mathrm{mM}$ silver nitrate solution for 24 hours. (B) UV/vis spectral analysis of culture supernatant containing the AgNPs over a wavelength range of $400-800 \mathrm{~nm}$ after 24 hours of reaction. Prominent peak for UV/vis spectra is visualized at $426 \mathrm{~nm}$. Optimization of physicochemical parameters for silver nanoparticle synthesis: (C) temperature, (D) pH, (E) concentration of silver nitrate, and (F) incubation time. The error bars represent mean \pm standard deviation.

Abbreviation: AgNPs, silver nanoparticles.

(5 $\mathrm{mM}$ and $10 \mathrm{mM} \mathrm{AgNO}_{3}$ salt). Earlier reports have shown that AgNPs synthesized using various microbes like Pseudomonas stutzeri AG259, Bacillus megaterium, K. pneumoniae, and Bacillus licheniformis exhibit a larger particle size of $200 \mathrm{~nm}$, $80-98.56 \mathrm{~nm}, 28.2-122 \mathrm{~nm}$, and $50 \mathrm{~nm}$, respectively; ${ }^{32-35}$ however, biologically synthesized AgNPs using D. radiodurans are comparatively of smaller size (16.82 nm). Nanoparticles with smaller size can have promising applications in biomedicine due to the advantage of increased surface area.

\section{FTIR}

FTIR measurements were performed to identify the possible biomolecules responsible for bioreduction, capping, and/or stabilizing the AgNPs synthesized using D. radiodurans. In order to obtain good signal-to-noise ratio of AgNPs, the spectrum was taken in the range $500-3,100 \mathrm{~cm}^{-1}$. Figure 4A shows the prominent intensity peaks at $1,591.30 \mathrm{~cm}^{-1}$, $1,395.39 \mathrm{~cm}^{-1}$, and $3,197.97 \mathrm{~cm}^{-1}$. The functional groups such as $\mathrm{C}-\mathrm{H}$ stretch, $\mathrm{CH}_{3}-\mathrm{R}, \mathrm{N}-\mathrm{H}, \mathrm{C}-\mathrm{O}-\mathrm{C}$, aromatic $\mathrm{C}-\mathrm{C}$ skeletal 

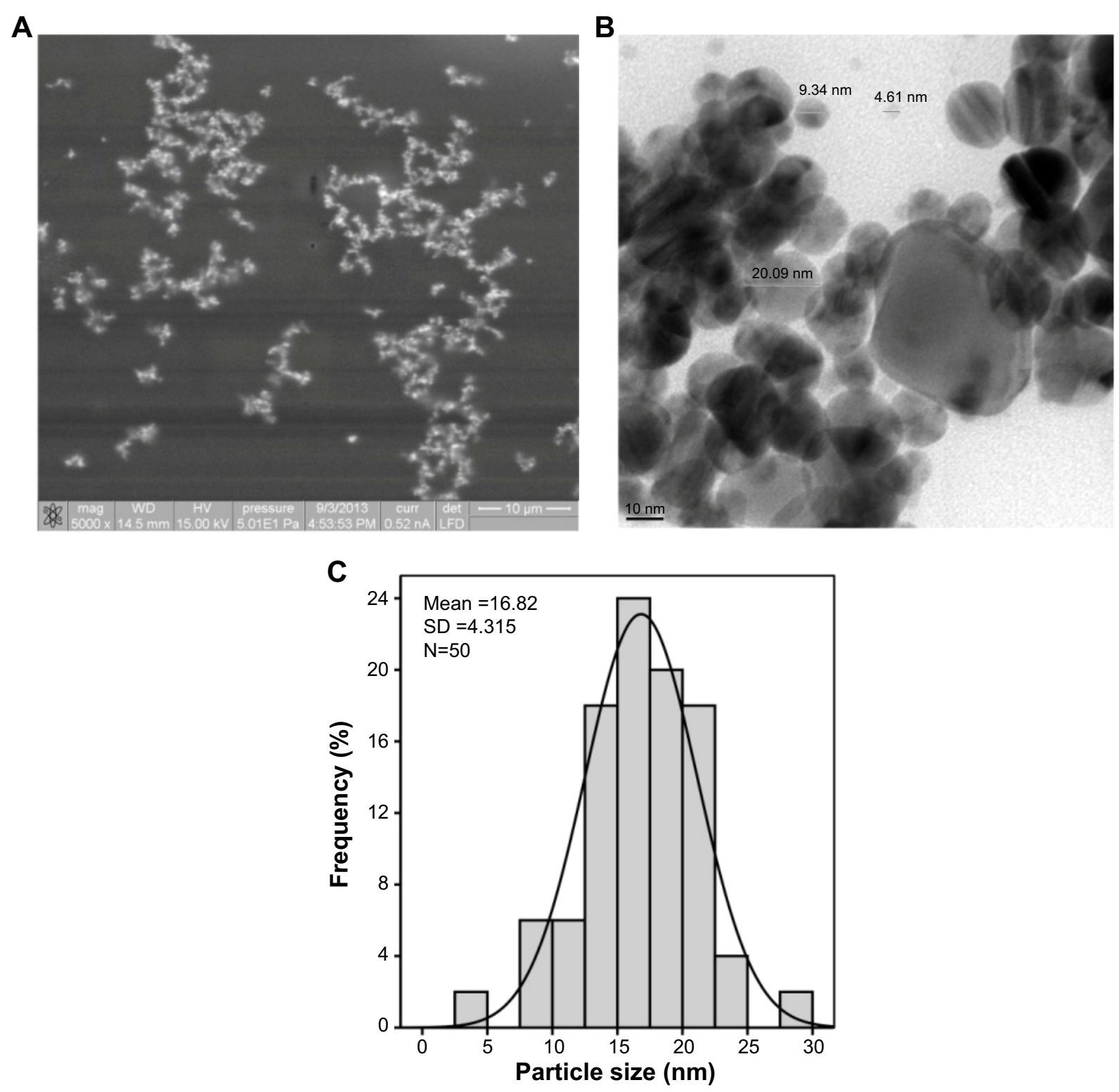

Figure 2 Morphology of synthesized AgNPs.

Notes: (A) Scanning electron microscopic observation of AgNPs at $\times 5,000$; insert bar corresponds to $10 \mu \mathrm{m}$. (B) TEM image of AgNPs; insert bar corresponds to $10 \mathrm{~nm}$. (C) Particle size histogram evaluated from corresponding TEM micrograph is shown in (B).

Abbreviations: AgNPs, silver nanoparticles; TEM, transmission electron microscopy.

vibrations, $-\mathrm{COO},-\mathrm{NO}_{3}$, thioester, and $\mathrm{S}-\mathrm{S}$ stretch were observed at different wave numbers. Sastry et al reported that functional groups like $-\mathrm{C}-\mathrm{O}-\mathrm{C}-,-\mathrm{C}=\mathrm{C}-$, and $-\mathrm{COO}$ are derived from heterocyclic compounds like proteins present in the fungal extract and are capping ligands of nanoparticles. ${ }^{36}$ In our study, the amide linkage and other functional groups revealed through the FTIR analysis may probably play a role in the interaction of synthesized nanoparticles with the proteins/ peptides of D. radiodurans, thereby stabilizing the AgNPs.

\section{Energy-dispersive spectroscopy}

Elemental analysis performed using EDX (Figure 4B) confirmed the presence of metallic AgNPs. In addition, the $\mathrm{Si}$ signal observed was most likely caused by X-ray emission from silicon wafer support used in EDX analysis. ${ }^{27}$

\section{XRD measurements}

The XRD technique is used to establish the metallic nature of particles. Figure $4 \mathrm{C}$ depicts the XRD pattern of AgNP films deposited on a glass substrate. XRD analysis of AgNPs synthesized using D. radiodurans showed clear diffraction peaks at $38.36,45.67,44.64$, and 77.420 , indexing the planes $211,111,200$, and 103 of the crystalline silver. Planes 211, 111, and 200 correspond to cubic structure of nanoparticles, while the plane 103 corresponds to hexagonal phase. ${ }^{37}$ It therefore suggests that the AgNPs synthesized 

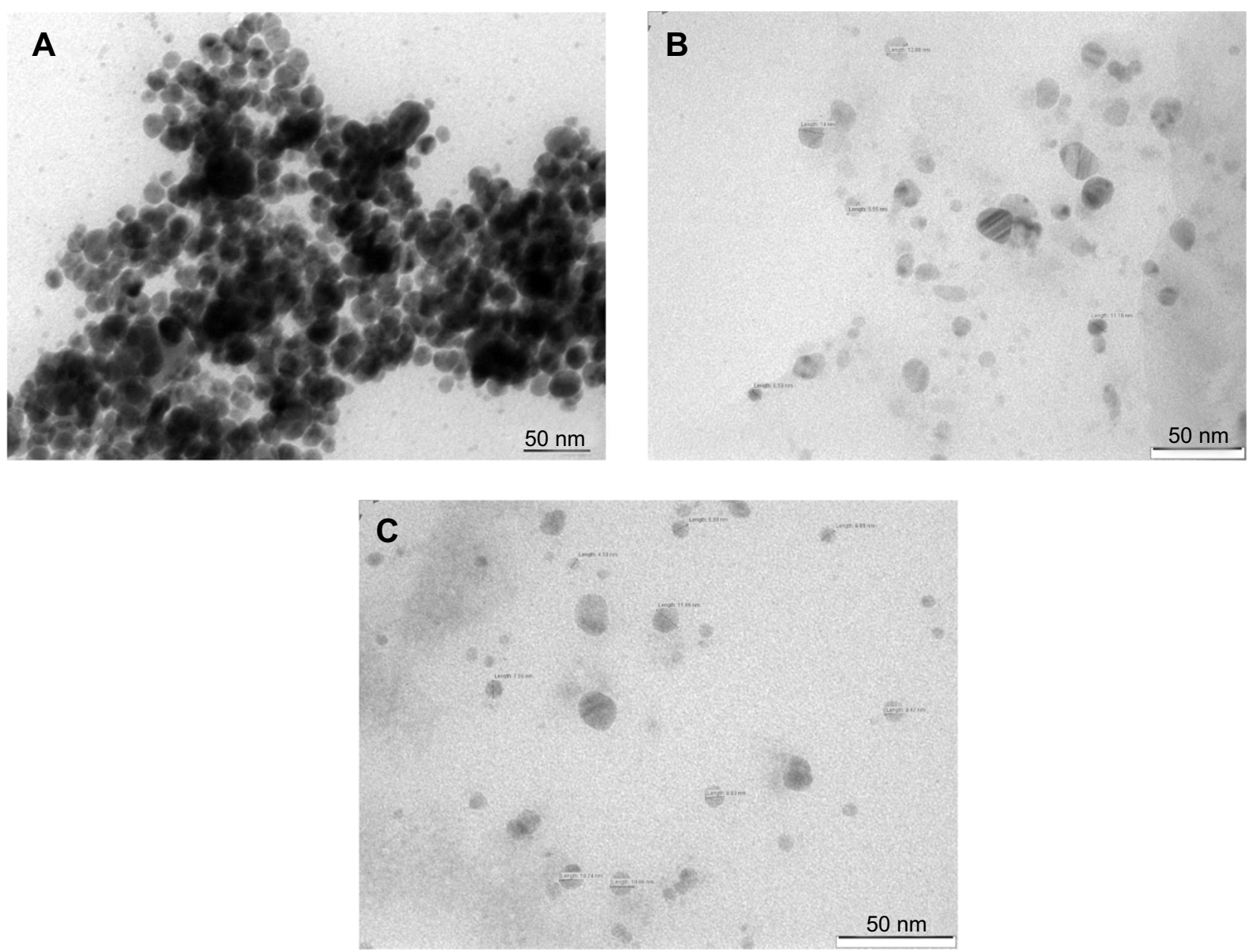

Figure 3 Transmission electron microscopic images of AgNPs.

Notes: AgNPs synthesized using different concentrations of $\mathrm{AgNO}_{3}$ : (A) $2.5 \mathrm{mM}$, (B) $5 \mathrm{mM}$, and (C) $10 \mathrm{mM}$. Insert bar corresponds to 50 nm. Abbreviation: AgNPs, silver nanoparticles.

using $D$. radiodurans are biphasic in nature. This slight shift in the peak positions indicated the presence of strain in the crystal structure, which is a characteristic of nanocrystallites. The data obtained were matched with the database of Joint Committee on Powder Diffraction Standards (file numbers 870718 and 721426). According to this match, the peaks $2.344,2.027$, and 1.984 correspond to silver, while the peak 2.799 corresponds to silica as the sample was prepared and scanned on a glass slide. The XRD data clearly indicated the crystalline structure of the AgNPs. Thus, the XRD pattern along with UV/vis spectra and TEM images provides an evidence for the presence of AgNPs.

\section{Antibacterial activity}

Several studies have demonstrated that biosynthesized AgNPs alone or in combination with antibiotics tend to have strong bactericidal activity against Gram-negative and Gram-positive bacteria ${ }^{38}$ including multidrug-resistant strains such as E. coli, P. aeruginosa, and S. aureus. ${ }^{39}$ In this study, the antibacterial activity of the synthesized AgNPs was investigated using the agar well diffusion method and standard dilution micromethod. The results for the inhibition zones and their average values obtained from agar well diffusion assay are shown in Figure 5A. In liquid growth experiments, 91\% growth inhibition was observed when $E$. coli $\left(10^{6} \mathrm{CFU} / \mathrm{mL}\right)$ was treated with $150 \mu \mathrm{g} / \mathrm{mL}$ concentration of AgNPs for 3 hours, and a decline in CFU per milliliter was seen from $1.54 \times 10^{7}$ (untreated control) to $1.42 \times 10^{6}$ (AgNPs treated), while in the case of Gram-positive $S$. aureus $\left(10^{6} \mathrm{CFU} / \mathrm{mL}\right)$, treatment with $150 \mu \mathrm{g} / \mathrm{mL}$ of AgNPs for 3 hours exhibited a $46 \%$ growth inhibition with CFU per milliliter reducing from $8.6 \times 10^{7}$ (untreated control) to $4.64 \times 10^{7}$ (AgNPs treated). Therefore, it was apparent that all bacterial cultures used in this study were inhibited by AgNPs. Gram-negative bacteria were highly suppressed by the AgNPs compared to Gram-positive bacteria. Among the Gram-negative bacteria, $P$. vulgaris was inhibited the most followed by E. coli and $P$. aeruginosa, while among the Gram-positive bacteria, $S$. aureus was more susceptible followed by B. subtilis. Antibacterial activity of AgNPs (160-200 $\mu \mathrm{g} / \mathrm{mL})$ against 

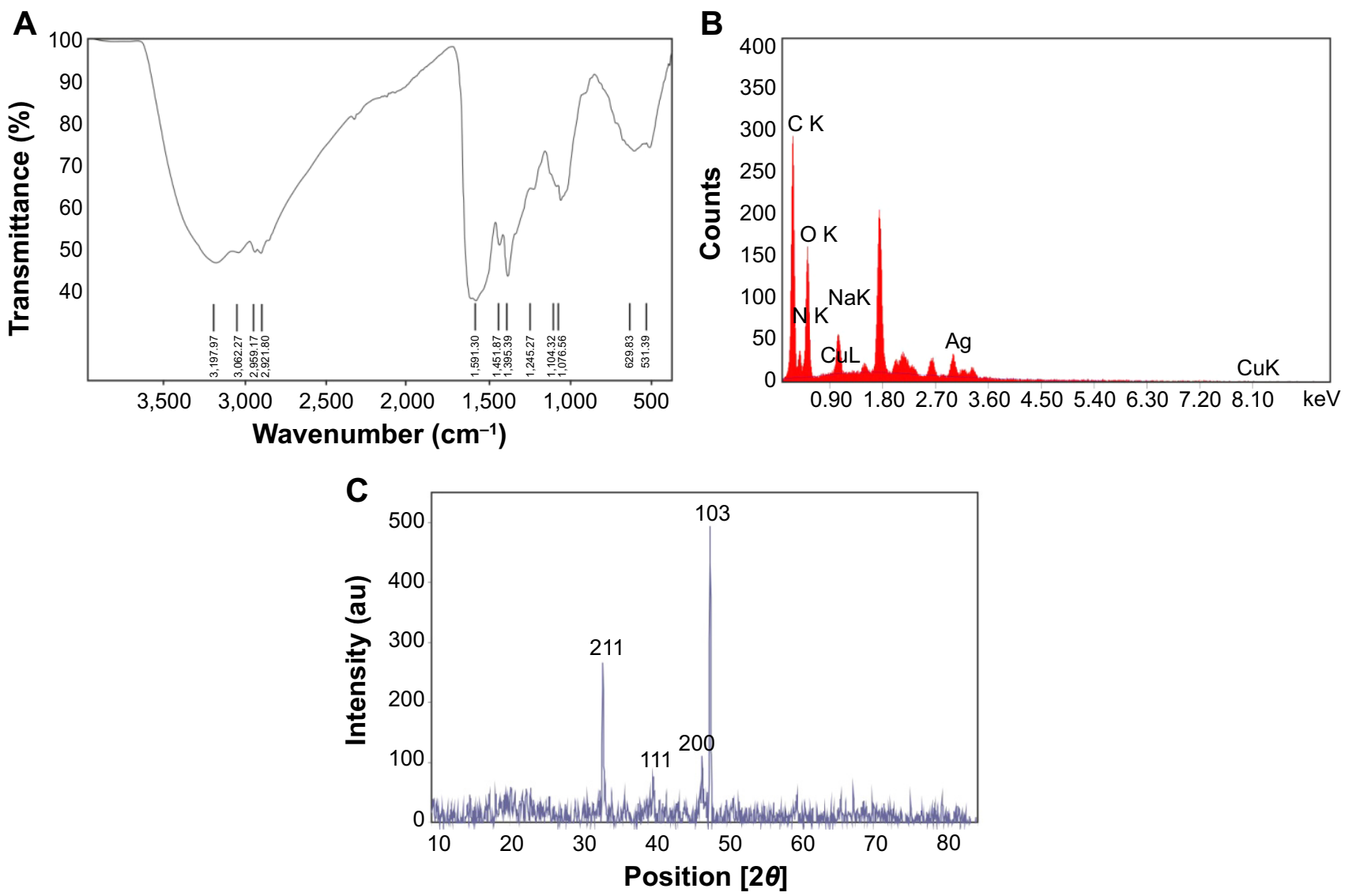

Figure 4 Characterization of silver nanoparticles.

Notes: (A) FTIR spectrum recorded from microbially synthesized silver nanoparticle powder using Deinococcus radiodurans. (B) EDX observation of biosynthesized AgNPs with their corresponding strong Ag signals at around $3 \mathrm{KeV}$. (C) XRD pattern of the AgNPs synthesized by the bacterium $D$. radiodurans in the form of a thin film deposited on a glass substrate. The Braggs reflections are identified in the XRD pattern.

Abbreviations: FTIR, Fourier transform infrared spectroscopy; EDX, energy-dispersive X-ray spectroscopy; AgNPs, silver nanoparticles; XRD, X-ray diffraction.

A

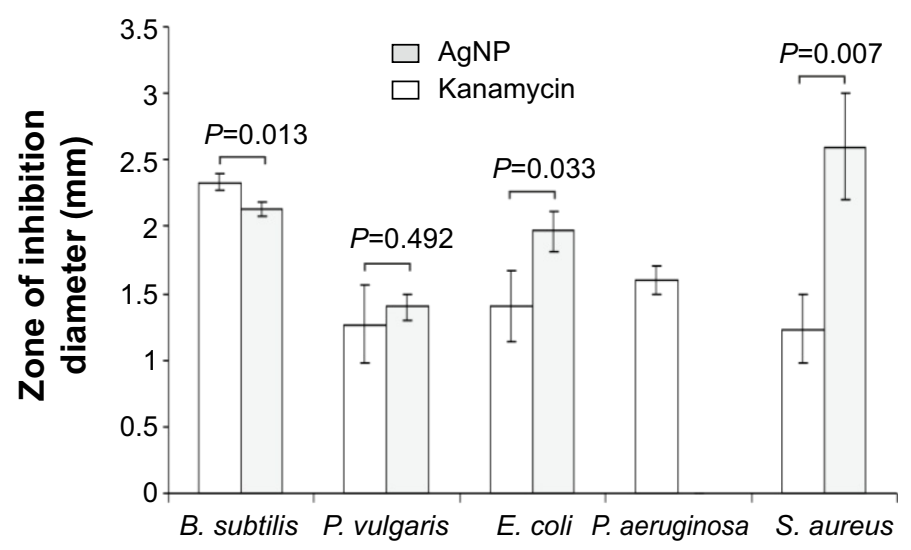

B

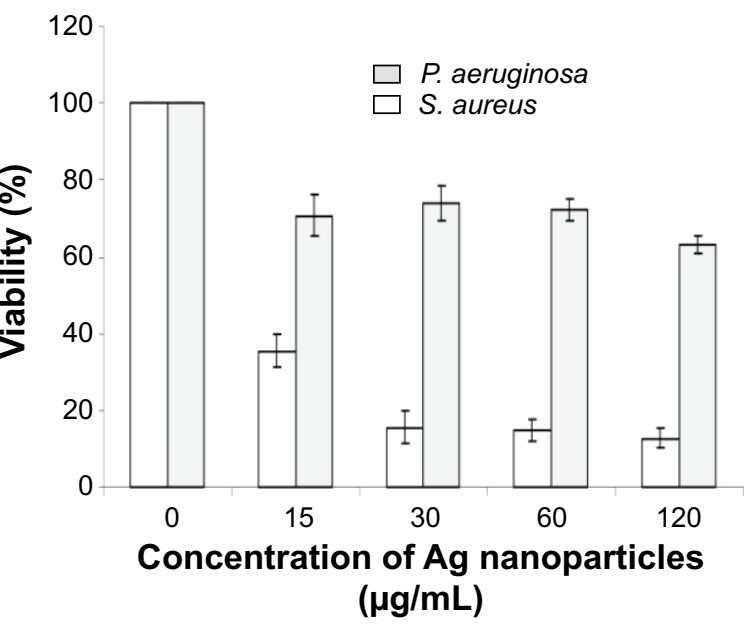

Figure 5 Antibacterial and Anti-biofouling activity of silver nanoparticles.

Notes: (A) Representative results of antimicrobial activity of nanoparticles against Gram-positive Bacillus subtilis and Staphylococcus aureus and Gram-negative Escherichia coli, Proteus vulgaris, and Pseudomonas aeruginosa. (B) Anti-biofouling activity of silver nanoparticles against Gram-negative $P$. aeruginosa and Gram-positive $S$. aureus. The figure depicts a graph showing percent viability of the $P$. aeruginosa (statistically significant $P=1.72 \times 10^{-6}$ [ANOVA] and $P<0.01\left[t\right.$-test]) and $S$. aureus $\left(P=4.64 \times 10^{-11}[\right.$ ANOVA] and $P<0.000$ I [t-test]) against the varying concentrations of silver nanoparticles.

Abbreviation: ANOVA, analysis of variance. 
B. subtilis, Bacillus cereus, E. coli, and P. aeruginosa has been reported. ${ }^{40-42}$ AgNPs synthesized using D. radiodurans exhibited an effective antibacterial activity at a concentration of $150 \mu \mathrm{g} / \mathrm{mL}$. Antibiotic resistance is the biggest challenge to the medical field for the treatment of infectious diseases, particularly due to the emergence of multidrug-resistant pathogenic strains. Thus, AgNPs synthesized in the present study could offer a potential as an effective antibacterial agent alone or in combination for the management of antibioticresistant bacterial diseases after completing the successful clinical trials. In earlier reports on antibacterial activity of AgNPs, it has been observed that maximum inhibition of AgNPs was against Gram-negative microorganisms as compared to Gram-positive microorganisms, ${ }^{43}$ which may be probably associated with the differences in their cell wall composition. ${ }^{39,44}$ However, the exact mechanism by which the AgNPs exert their antibacterial effect remains to be elucidated.

\section{Anti-biofouling assay}

Along with antibacterial activity, we evaluated the potential of AgNPs as an anti-biofouling agent against $S$. aureus and multidrug-resistant $P$. aeruginosa. AgNPs were capable of inhibiting the biofilm formation in both the microorganisms, S. aureus being more susceptible as compared to P. aeruginosa. The biofilm formation by the bacterial strains was inhibited in a dose-dependent manner (Figure 5B). Decrease in biofilm formation was observed with increasing concentration of AgNPs. This indicates that AgNPs synthesized by $D$. radiodurans may provide a good alternative source of anti-biofouling compounds.

\section{Anticancer activity}

Microbially synthesized AgNPs have been well characterized as an antimicrobial agent. Although there are several reports on antitumor/anticancer activity of AgNPs synthesized using various plants, ${ }^{45}$ there is limited information about antitumor/anticancer potential of AgNPs generated using microbial synthesis methods. This study is focused on determining cytotoxic effects of AgNPs on MCF-7 human breast cancer cells.

\section{Optical microscopic study}

MCF-7 cells exposed to different concentrations of AgNPs had alterations in cell shape and morphology indicating unhealthy cells, whereas untreated control cells exhibited no change in morphology (Figure 6). Nanoparticle-treated cells appeared to be clustered, and cell-spreading pattern was restricted as compared to untreated cells.

\section{MTT assay}

Cell viability and metabolic activity studies were conducted using MTT assay by exposing MCF-7 cells to AgNPs at 0-30 $\mu \mathrm{g}$ concentrations for 24 hours. The results of MTT assay showed a dose-dependent decrease in percent viability of the cells (Figure 7A). In the present study, cytotoxicity data were fitted to a sigmoidal curve, and a four-parameter nonlinear logistic model was used to calculate the $\mathrm{LD}_{50}$ of
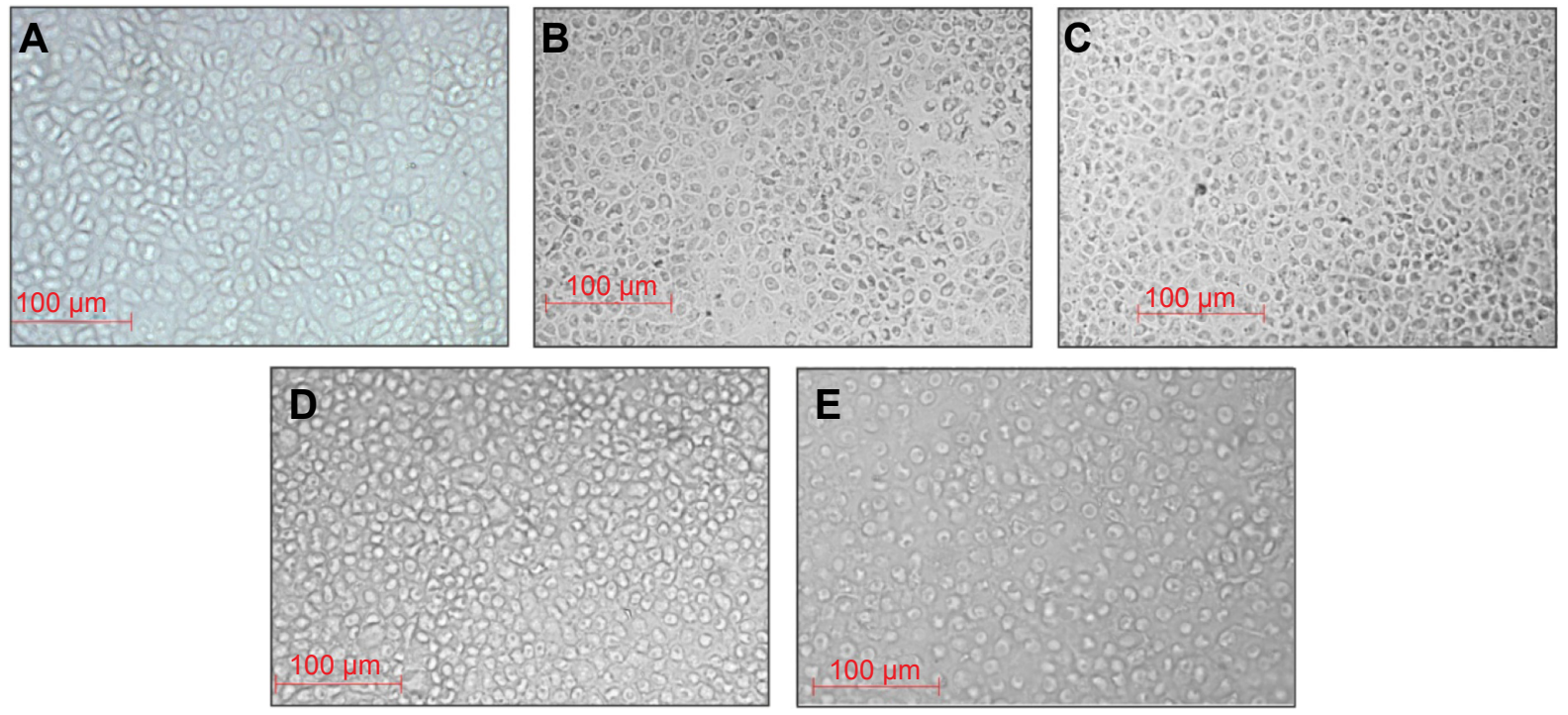

Figure 6 Cytotoxic activity of AgNPs.

Notes: Effect of AgNPs on human breast cancer cell line (MCF-7) at different concentrations: (A) control, (B) $1.65 \mu \mathrm{g} / \mathrm{mL}$, (C) $3.75 \mu \mathrm{g} / \mathrm{mL},(\mathbf{D}) 7.5 \mu \mathrm{g} / \mathrm{mL}$, and (E) I5 $\mu \mathrm{g} / \mathrm{mL}$. Abbreviation: AgNPs, silver nanoparticles. 

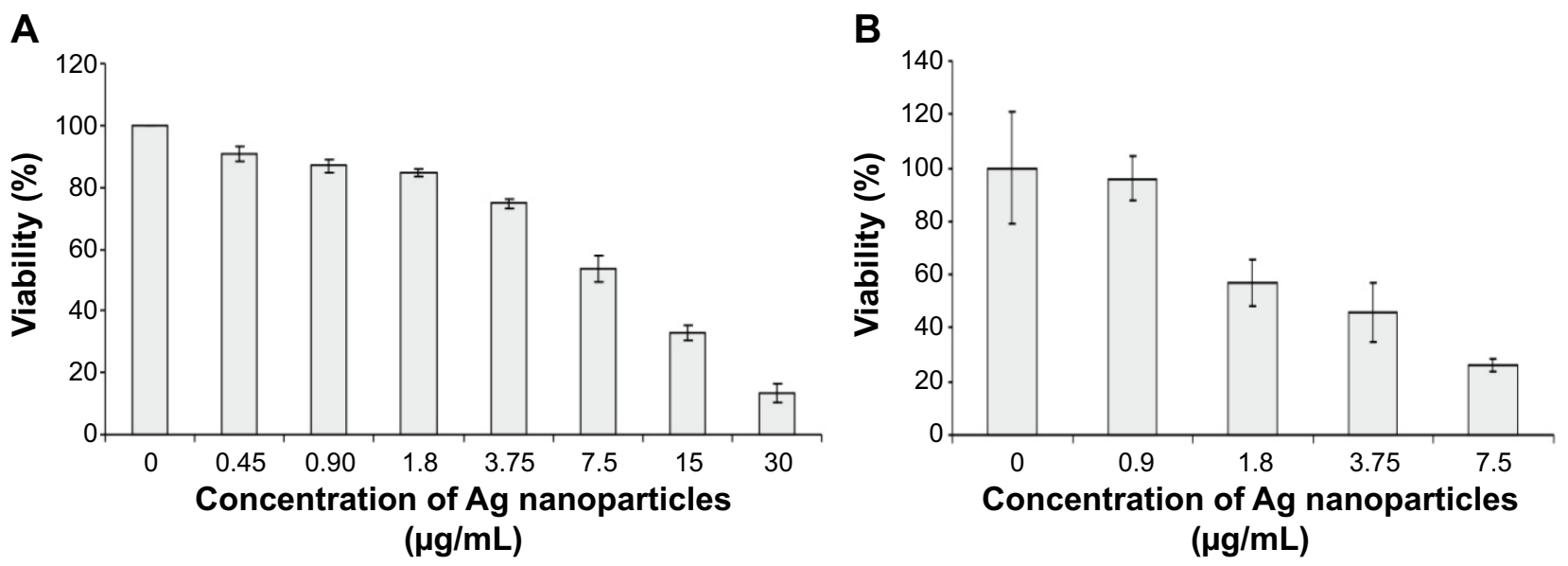

Figure 7 Percent viability of MCF-7 human breast cancer cells upon treatment with AgNPs.

Notes: $(A)$ Graph showing percent viability of human breast cancer cell line (MCF-7) against various concentrations of the synthesized silver nanoparticles $\left(P=2.15 \times 10^{-17}\right.$ [ANOVA]). (B) Colony-forming assay representing the percent viability of MCF-7 cell line against different concentrations of $A_{g N P s}$ below $L_{50}$ after 10 days.

Abbreviations: ANOVA, analysis of variance; AgNPs, silver nanoparticles; $\mathrm{LD}_{50}$, lethal dose.

nanomaterials that caused a 50\% inhibition in comparison to untreated controls, which was $7.9 \mu \mathrm{g} / \mathrm{mL}$. All $\mathrm{LD}_{50}$ values were calculated using the average cytotoxicity data of the three independent experimental results and their associated errors. Exposure to increasing concentrations of AgNPs showed a dose-dependent cytotoxicity on the cancer cell line. It is reported that the $\mathrm{LD}_{50}$ of AgNPs synthesized using various methods against MCF-7 breast cancer cell lines is in the range of $10-30 \mu \mathrm{g} / \mathrm{mL}^{46}$ In the present study, the $\mathrm{LD}_{50}$ of AgNPs synthesized using $D$. radiodurans was found to be $7-8 \mu \mathrm{g} / \mathrm{mL}$, which suggests that these nanoparticles are effective at a lower concentration against MCF-7 human breast cancer cell line compared to AgNPs synthesized using other sources. It is well studied that cytotoxicity of nanoparticles is size dependent with smaller nanoparticles entering the cells more easily and thus are more efficient than larger ones. ${ }^{47}$ It is likely that the smaller size of AgNPs (average size of $16.82 \mathrm{~nm}$ ) generated in this study using $D$. radiodurans may be one of the factors, and these particles could be further exploited for potential applications in cytotoxicity and anticancer activity.

\section{Clonogenic survival}

Clonogenic assay indicates the proliferative capacity of a single cell upon nanoparticle exposure for 10 days. MCF-7 cells were incubated with AgNPs and then stained with crystal violet stain. The recorded colony count represents the number of viable cells. The results of the colony-forming assay for cells treated with the AgNPs below $\mathrm{LD}_{50}$ for 24 hours are presented in Figure 7B. It represents the dose response indicating the decrease in the colony number with the increasing concentration of AgNPs, thus demonstrating the effective inhibition of growth and proliferation of the MCF-7 cancer cell line.

\section{Conclusion}

D. radiodurans is able to withstand $5,000 \times$ more radiation than any other known living organism and demonstrates ability to withstand exposure to desiccation. It is known to possess the ability to repair double-strand breaks, and metals such as manganese have been shown to have a role in radiation resistance. We report here a simple, rapid, and efficient method for the synthesis and extracellular accumulation of AgNPs using D. radiodurans. The synthesized AgNPs are spherical in shape and have an average particle size of $16.82 \mathrm{~nm}$. We have demonstrated the potential of these AgNPs for several applications. They exhibited excellent broad-spectrum antimicrobial activity against both Gram-positive and Gram-negative bacteria and anti-biofouling activity against $P$. aeruginos $a$ and $S$. aureus. Inhibitory effect of AgNPs on multidrug-resistant P. aeruginosa was also evident. AgNPs also showed effective anticancer activity against human breast cancer cell line (MCF-7). The cytotoxicity and mortality data highlight these AgNPs as potential anticancer agents. It will be possible to scale up AgNPs synthesis using D. radiodurans and explore possible applications based on its anticancer and antiproliferative activity. The biosynthesized AgNPs have proved to be potential candidates for medical applications where antifouling, antimicrobial, and cytotoxic activities are highly essential. Since $D$. radiodurans can sustain radiations, it may offer advantage over other organisms for on-field applications where the nanoparticle synthesis ability can be explored for bioremediation. In recent years, radioactive nanoparticles 
have been explored as cancer therapeutic and imaging agents. Till date, fabrication of radioactive nanoparticles has not been performed using microorganism; therefore, D. radiodurans may serve as a promising candidate for the synthesis of radioactive nanoparticles.

\section{Acknowledgment}

This research was funded by the University Grant Commission (Government of India) under University with Potential for Excellence Phase-II Nanobiotechnology.

\section{Authors contribution}

RK and NS contributed equally in carrying out all experiments and jointly analyzed the data sets. DND and DDD conceived the experiments, supervised, and provided major intellectual inputs. All authors assisted with drafting the article and critically revised it, and all have approved the final article.

\section{Disclosure}

The authors report no conflicts of interest in this work.

\section{References}

1. Jain J, Arora S, Rajwade JM, Omray P, Khandelwal S, Paknikar KM. Silver nanoparticles in therapeutics: development of an antimicrobial gel formulation for topical use. Mol Pharm. 2009;6:1388-1401.

2. Kalele SA, Kundu AA, Gosavi SW, Deobagkar DN, Deobagkar DD, Kulkarni SK. Rapid detection of Escherichia coli by using antibody conjugated silver nanoshells. Small. 2006;2:335-338.

3. Kalele SA, Ashtaputre SS, Hebalkar NY, et al. Optical detection of antibody using silica "silver core" shell particles. Chem Phys Lett. 2005;404:136-141.

4. Prabhu S, Poulose EK. Silver nanoparticles: mechanism of antimicrobial action, synthesis, medical applications, and toxicity effects. Int Nano Lett. 2012;2:1-10.

5. Morley KS, Webb PB, Tokareva NV, et al. Synthesis and characterization of advanced UHMWPE/silver nanocomposites for biomedical applications. Eur Polym J. 2007;43:307-314.

6. Pariser RJ. Generalized argyria. Clinicopathologic features and histochemical studies. Arch Dermatol. 1978;114:373-377.

7. Panyala NR, Pena-Mendez EM, Havel J. Silver or silver nanoparticles: a hazardous threat to the environment and human health? J Appl Biomed. 2008;6:117-129.

8. Thakkar KN, Mhatre SS, Parikh RY. Biological synthesis of metallic nanoparticles. Nanomedicine. 2012;6:257-262.

9. Xie J, Lee JY, Wang DIC, Ting YP. Silver nanoplates: from biological to biomimetic synthesis. ACS Nano. 2007;1:429-439.

10. Gericke M, Pinches A. Biological synthesis of metal nanoparticles. Hydrometallurgy. 2006;83:132-140.

11. Shivaji S, Madhu S, Singh S. Extracellular synthesis of antibacterial silver nanoparticles using psychrophilic bacteria. Process Biochem. 2011;46:1800-1807.

12. Kim Y, Lee BG, Roh Y. Microbial synthesis of silver nanoparticles. J Nanosci Nanotechnol. 2013;13:3897-3900.

13. Nies DH. Microbial heavy-metal resistance. Appl Microbiol Biotechnol. 1999;51:730-750.

14. Lemire JA, Harrison JJ, Turner RJ. Antimicrobial activity of metals: mechanisms, molecular targets and applications. Nat Rev Microbiol. 2013;11:371-384.
15. Yates MD, Cusick RD, Logan BE. Extracellular palladium nanoparticle production using Geobacter sulfurreducens. ACS Sustain Chem Eng. 2013;1:1165-1171.

16. Konishi Y, Tsukiyama T, Tachimi T, Saitoh N, Nomura T, Nagamine S. Microbial deposition of gold nanoparticles by the metal-reducing bacterium Shewanella algae. Electrochim Acta. 2007;53:186-192.

17. Moon JW, Roh Y, Lauf RJ, Vali H, Yeary LW, Phelps TJ. Microbial preparation of metal-substituted magnetite nanoparticles. J Microbiol Methods. 2007;70:150-158.

18. Fredrickson JK, Kostandarithes HM, Li SW, Plymale AE, Daly MJ. Reduction of Fe (III), Cr (VI), U (VI), and Tc (VII) by Deinococcus radiodurans R1. Appl Environ Microbiol. 2000;66:2006-2011.

19. Brim H, McFarlan SC, Fredrickson JK, et al. Engineering Deinococcus radiodurans for metal remediation in radioactive mixed waste environments. Nat Biotechnol. 2000;18:85-90.

20. Brim H, Osborne JP, Kostandarithes HM, Fredrickson JK, Wackett LP, Daly MJ. Deinococcus radiodurans engineered for complete toluene degradation facilitates Cr (VI) reduction. Microbiology. 2006; 152:2469-2477.

21. Appukuttan D, Rao AS, Apte SK. Engineering of Deinococcus radiodurans $\mathrm{R} 1$ for bioprecipitation of uranium from dilute nuclear waste. Appl Environ Microbiol. 2006;72:7873-7878.

22. Mark SS, Bergkvist M, Yang X, et al. Bionanofabrication of metallic and semiconductor nanoparticle arrays using S-layer protein lattices with different lateral spacings and geometries. Langmuir. 2006;22:3763-3774.

23. Nathan P, Law EJ, Murphy DF, MacMillan BG. A laboratory method for selection of topical antimicrobial agents to treat infected burn wounds. Burns. 1978;4:177-187.

24. Stepanović S, Vuković D, Hola V, et al. Quantification of biofilm in microtiter plates: overview of testing conditions and practical recommendations for assessment of biofilm production by staphylococci. APMIS. 2007;115:891-899.

25. Carmichael J, DeGraff WG, Gazdar AF, Minna JD, Mitchell JB. Evaluation of a tetrazolium-based semiautomated colorimetric assay: assessment of chemosensitivity testing. Cancer Res. 1987;47:936-942.

26. Wiley BJ, Im SH, Li ZY, McLellan J, Siekkinen A, Xia Y. Maneuvering the surface plasmon resonance of silver nanostructures through shape-controlled synthesis. J Phys Chem B. 2006;110:15666-15675.

27. Huang H, Yang X. Synthesis of polysaccharide-stabilized gold and silver nanoparticles: a green method. Carbohydr Res. 2004;339: 2627-2631.

28. Gurunathan S, Kalishwaralal K, Vaidyanathan R, et al. Biosynthesis, purification and characterization of silver nanoparticles using Escherichia coli. Colloids Surf B Biointerfaces. 2009;74:328-335.

29. Murphy CJ, Gole AM, Hunyadi SE, OrendorffCJ. One-dimensional colloidal gold and silver nanostructures. Inorg Chem. 2006;45:7544-7554.

30. Chen J, Wiley BJ, Xia Y. One-dimensional nanostructures of metals: large-scale synthesis and some potential applications. Langmuir. 2007; 23:4120-4129.

31. Binupriya AR, Sathishkumar M, Yun SI. Myco-crystallization of silver ions to nanosized particles by live and dead cell filtrates of Aspergillus oryzae var. viridis and its bactericidal activity toward Staphylococcus aureus KCCM 12256. Ind Eng Chem Res. 2009;49:852-858.

32. Klaus T, Joerger R, Olsson E, Granqvist CG. Silver-based crystalline nanoparticles, microbially fabricated. Proc Natl Acad Sci U S A. 1999; 96:13611-13614.

33. Saravanan M, Vemu AK, Barik SK. Rapid biosynthesis of silver nanoparticles from Bacillus megaterium (NCIM 2326) and their antibacterial activity on multi drug resistant clinical pathogens. Colloids Surf $B$ Biointerfaces. 2011;88:325-331.

34. Shahverdi AR, Minaeian S, Shahverdi HR, Jamalifar H, Nohi AA. Rapid synthesis of silver nanoparticles using culture supernatants of Enterobacteria: a novel biological approach. Process Biochem. 2007;42:919-923.

35. Kalimuthu K, Suresh Babu R, Venkataraman D, Bilal M, Gurunathan S. Biosynthesis of silver nanocrystals by Bacillus licheniformis. Colloids Surf B Biointerfaces. 2008;65:150-153. 
36. Sastry M, Ahmad A, Islam Khan M, Kumar R. Biosynthesis of metal nanoparticles using fungi and actinomycete. Curr Sci. 2003;85: $162-170$.

37. Sathishkumar M, Sneha K, Yun YS. Immobilization of silver nanoparticles synthesized using Curcuma longa tuber powder and extract on cotton cloth for bactericidal activity. Bioresour Technol. 2010;101:7958-7965.

38. Dhanalakshmi M. Silver nanoparticles and its antibacterial activity. Int J Pharm Biol Arch. 2013;4:819-826.

39. Rai MK, Deshmukh SD, Ingle AP, Gade AK. Silver nanoparticles: the powerful nanoweapon against multidrug-resistant bacteria. $J$ Appl Microbiol. 2012;112:841-852.

40. Bankura KP, Maity D, Mollick MM, et al. Synthesis, characterization and antimicrobial activity of dextran stabilized silver nanoparticles in aqueous medium. Carbohydr Polym. 2012;89:1159-1165.

41. Ruparelia JP, Chatterjee AK, Duttagupta SP, Mukherji S. Strain specificity in antimicrobial activity of silver and copper nanoparticles. Acta Biomater. 2008;4:707-716.

42. Kim JS, Kuk E, Yu KN, et al. Antimicrobial effects of silver nanoparticles. Nanomedicine. 2007;3:95-101.
43. Guzman M, Dille J, Godet SP. Synthesis and antibacterial activity of silver nanoparticles against Gram-positive and Gram-negative bacteria. Nanomedicine. 2012;8:37-45.

44. Radzig MA, Nadtochenko VA, Koksharova OA, Kiwi J, Lipasova VA, Khmel IA. Antibacterial effects of silver nanoparticles on Gramnegative bacteria: influence on the growth and biofilms formation, mechanisms of action. Colloids Surf B Biointerfaces. 2013;102: 300-306.

45. Raghunandan D, Ravishankar B, Sharanbasava G, et al. Anti-cancer studies of noble metal nanoparticles synthesized using different plant extracts. Cancer Nanotechnol. 2011;2:57-65.

46. Lima R, Seabra AB, Duran N. Silver nanoparticles: a brief review of cytotoxicity and genotoxicity of chemically and biogenically synthesized nanoparticles. J Appl Toxicol. 2012;32:867-879.

47. Liu W, Wu Y, Wang C, et al. Impact of silver nanoparticles on human cells: effect of particle size. Nanotoxicology. 2010;4:319-330.
International Journal of Nanomedicine

\section{Publish your work in this journal}

The International Journal of Nanomedicine is an international, peerreviewed journal focusing on the application of nanotechnology in diagnostics, therapeutics, and drug delivery systems throughout the biomedical field. This journal is indexed on PubMed Central,

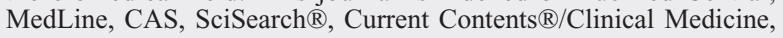

\section{Dovepress}

Journal Citation Reports/Science Edition, EMBase, Scopus and the Elsevier Bibliographic databases. The manuscript management system is completely online and includes a very quick and fair peer-review system, which is all easy to use. Visit http://www.dovepress.com/ testimonials.php to read real quotes from published authors. 